\title{
Investigating the Wear Behaviours of New Type Curvilinear Gears
}

\author{
M. UZUN* AND K. YILDIZ
}

Bingol University, Faculty of Engineering, Department of Mechanical Engineering, Bingol, Turkey

\begin{abstract}
In this study, the wear behaviors of curvilinear involute-profile gears, which were intended to be used in the industry and manufactured successfully, have been identified. For this purpose, the gears have been manufactured and attached to a FZG gear analysis bench; then, they were compared with spur gears by examining the behaviors of curvilinear involute-profile gears under different loads at different speeds, certain cycles. As a result of these analyses conducted, it has been determined that the wear behaviors of these newly manufactured curvilinear involute-profile gears are better than the behaviors of the spur gears, and in the increasing number of cycles, the curvilinear involute-profile gears had less wear than the spur gears have.
\end{abstract}

DOI: 10.12693/APhysPolA.128.B-337

PACS: $81.40 . P q$

\section{Introduction}

Gears are important machine elements that are used for transmission of power and movement. Regular and proper operation of a machine depends on transmission of the movement. When failure occurs in a gear used in the system, it is needed to replace that gear without stopping the production, which is particularly important for the gears used in the continuous production lines [1]. Surface wear of gears is an important type of damage. The gears work in dry or oily media are subject to some wear. It has been believed that this slight wear improves the conditions of contact points. This belief may be true for some cases, but it is not always true. Because the gears in contact with each other have uniform structures and rolling shear may be affected by this condition [2]. There are many factors that cause wear but their effects cannot be calculated exactly, there are various methods developed to determine these effects [3]. In gear technology, the wear of two gears in contact has been the subject of the studies many times. New models predicting this wear have been developed [4-6]. Many machine parts show the fatigue behavior. Gears are also important machine elements that show fatigue behaviors. Pitting, corrosion and other effects of fatigue occur along with one line coupling line, in which Hertzian pressure is at maximum level [6]. Since the contact is in the form of rolling shear, the changes and corrosion on the gears after wear may impair contact conditions [7-8]. As a result of this, bending fatigue may occur at the tooth profile under large loadings. Excessive wear of the gear tooth profile causes the loss. The concave-convex gears have been designed and manufactured along with the standard gears [9-10]. The concave-convex gears manufactured (Table I) have been analyzed by using the finite

\footnotetext{
*corresponding author; e-mail: muzun@bingol.edu.tr
}

TABLE I

Geometric dimensions of the gears.

\begin{tabular}{c|c}
\hline \hline module $[\mathrm{mm}]$ & 6 \\
number of teeth & 15 \\
profile shift factor & 0.133 \\
pressure angle $\left[^{\circ}\right]$ & 20 \\
operation pressure angle $\left[^{\circ}\right]$ & 22.439 \\
diameter of generating pitch circle & 90 \\
centre distance $[\mathrm{mm}]$ & 91.5 \\
contact ratio & 1.406 \\
width [mm] & 20
\end{tabular}

elements method and the detection of the noise level was performed [11]. In this study, the wear behaviors of the gears were investigated by applying two different loads, keeping the tooth width fixed under a pressure close to the Hertzian pressure and keeping the speed constant.

\section{Material and method}

We know that the shear on the vertical surface profiles causes adhesion wears. The relationship between shear rate, temperature and load distribution is given in

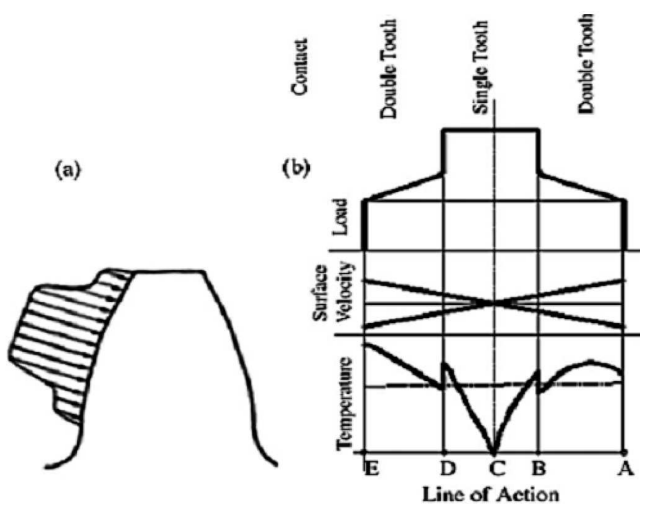

Fig. 1. (a) Load distribution, (b) load, surface velocity, temperature variation with line of action [9]. 
Fig. 1. As it can be seen in Fig. 1, the shear rate starts from point $\mathrm{E}$ toward point $\mathrm{A}$ with an increase. This indicates that the speed of the tooth increases from top to the bottom. The direction of shear movement changes at point $\mathrm{C}$. Increasing temperatures and corrosion are observed on the tooth caused by high speed (Fig. 1) [12].

In the experiments, AISI 4140 steel were used as pinion gear material. The hardness of this material has been red as 53-57 Rc under a load of 150 daN. The chemical combination of this material is given in Table II.

During the study, the PEEK plastic material was used as the gear material being rotated. The purpose of using this material is that the wear behaviour of the gears can be easily monitored under low loadings at shorter durations in the experiments. Thus, the comparison of wear behaviours between concave-convex gears and spur gears could be easily done. The strength values of PEEK material are given in Table III.

TABLE II

Chemical combination of the materials.

\begin{tabular}{c|c|c|c|c|c|c|c}
\hline \hline \multicolumn{6}{c}{ Chemical composition (wt.\%) of the gear material } \\
\hline $\mathrm{C}$ & $\mathrm{Si}$ & $\mathrm{Mo}$ & $\mathrm{Mn}$ & $\mathrm{Fe}$ & $\mathrm{P}$ & $\mathrm{S}$ & $\mathrm{Cr}$ \\
\hline 0.412 & 0.23 & 0.5 & 0.665 & 97.5 & 0.013 & 0.014 & 1.15
\end{tabular}

PEEK materials properties.

TABLE III

\begin{tabular}{c|c|c|c|c|c}
\hline \hline $\begin{array}{c}\text { Yield stress } \sigma_{a k} \\
{\left[\mathrm{~N} / \mathrm{mm}^{2}\right]}\end{array}$ & $\begin{array}{c}\text { Under yield stress } \\
\text { strain } \varepsilon_{s}[\%]\end{array}$ & $\begin{array}{c}\text { Break stress } \sigma_{K} \\
{\left[\mathrm{~N} / \mathrm{mm}^{2}\right]}\end{array}$ & $\begin{array}{c}\text { Under break stress } \\
\text { strain } \varepsilon_{R}[\%]\end{array}$ & $\begin{array}{c}\text { Impact resistance } \\
a_{n}\left[\mathrm{~kJ} / \mathrm{m}^{2}\right]\end{array}$ & $\begin{array}{c}\text { Modulus of elasticity } \\
E_{t}\left[\mathrm{~N} / \mathrm{mm}^{2}\right]\end{array}$ \\
\hline 110 & 4.9 & 75 & 20 & 15 & 4400
\end{tabular}

The reason of using steel as the pinion gear is enabling the transfer of heat easier occurring during operation. In this way, the plastic deformation, which may result from overheating on the surface of the gear, is prevented. The corrosion test of the gears was performed on the bench of Forschungsstelle für Zahnräder und Getriebebau (FZG), which has have different tooth centers. The binding of the gears to the bench is given in Fig. 2. This bench has a loading device [13-14]. Two different amounts of torque as $120 \mathrm{Nm}$ and $190 \mathrm{Nm}$ were applied to both gears. The rotation rate of the pinion gear has been taken as $250 \mathrm{rev} / \mathrm{min}[15-16]$.

A total of 8 gears were subjected to the abrasion test at rotation rates $1.8 \times 10^{5}$ and $36 \times 10^{5} \mathrm{rev} / \mathrm{min}$, where two spur gears and two concave-convex toothed gears were manufactured for each torque value. During the study, the temperature changes occurring at the contact points of the gears have also been detected. The measurements of the gears at 8 contact points, given in Fig. 3, have been performed prior to the experiments. 3D models are given in Fig. 4.

For this operation, the three-dimensional measuring arm, which is the Edge model of FARO firm, has been used. After performing all the measurements on this bench, which has an accuracy of $0.001 \mathrm{~mm}$, the amounts of wear for the same points are presented in Fig. 5 . In addition, three-dimensional laser scanning device is used scanned gears. Before the experiment, the 3D model was created. After creating 3D model of the following experiments, measurements were performed at specified points and abrasion values were determined. Then, the weight of each individual gear was measured. After completion of the experiment, all the gears were re-weighed and the decrease in weight caused by wear was determined.

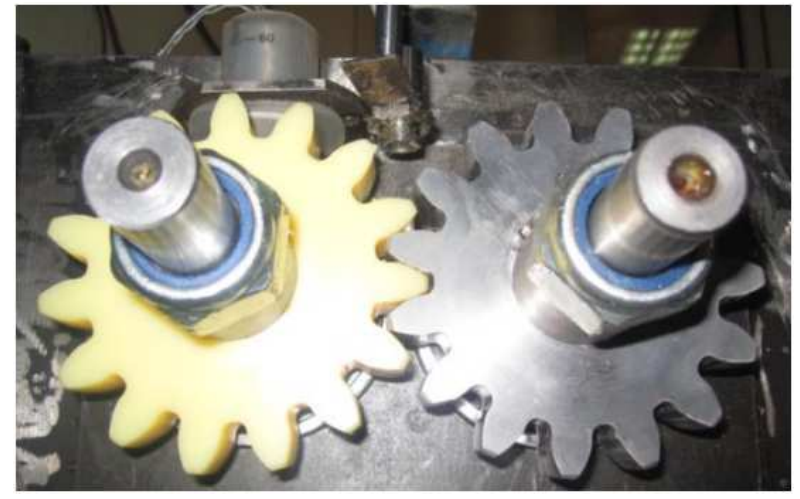

Fig. 2. The position of gears in the experimental set.
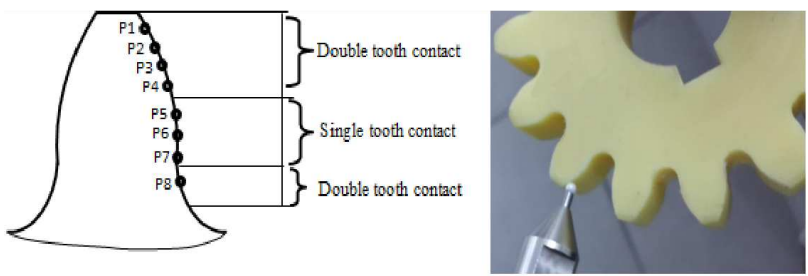

Fig. 3. Measurement points of the gears.

\section{Results and discussion}

The aim of this study is providing a comparison for the wear resistance between the firstly manufactured concave-convex involute gears and spur gears by comparing these two types of gears with each other. For this purpose, these two gears, which have the same dimension values, were subjected to abrasion test by using a FZG 


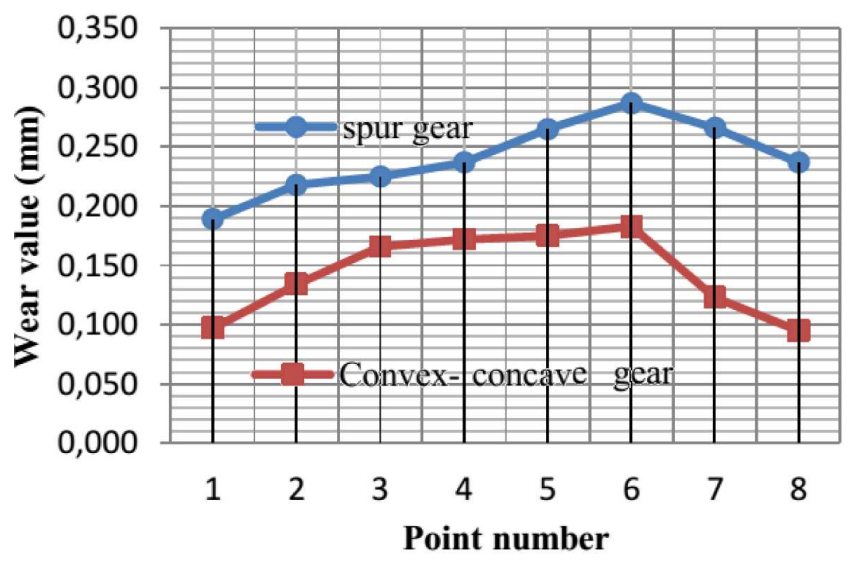

Fig. 4. Wear value on midpoint tooth flank of gears.
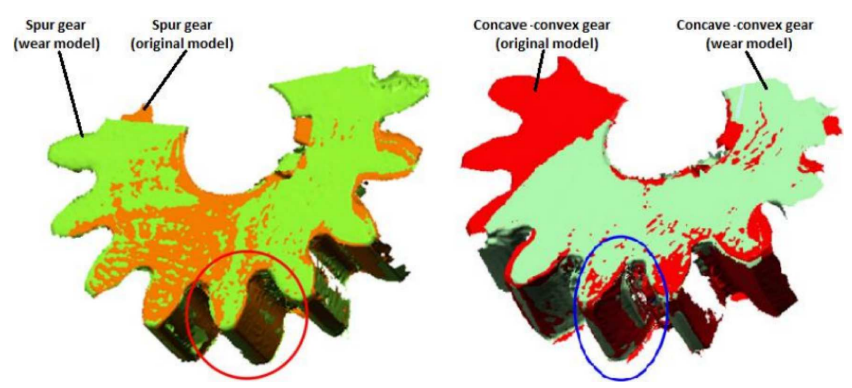

Fig. 5. Scan 3D model of original gear and wear gear.

bench. The weight losses of the gears occurred as a result of abrasion is given in Table IV.

The wear values on the surface of the gears have been measured under the Hertzian pressure through the gripping surface.

Three-dimensional laser scanning device is scanned with gears. Before the experiment, Gears 3D model was created. After creating 3D model (given in Fig. 4) the

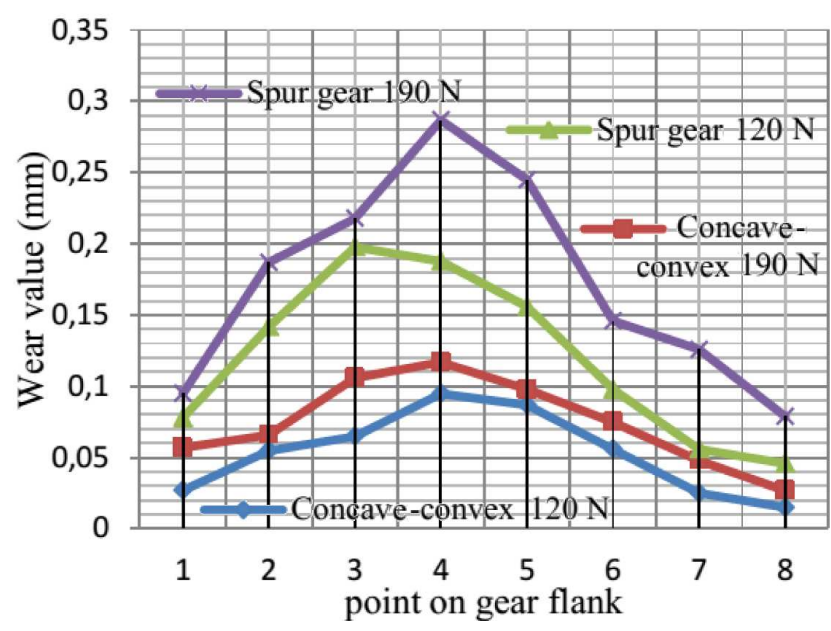

Fig. 6. Measured wear value on midpoint tooth flank of gears with laser scan method after 3600000 cycles.
TABLE IV

The weight loss in the gears after the abrasion test.

\begin{tabular}{c|c|c}
\hline \hline \multirow{2}{*}{$\begin{array}{c}\text { gear type } \\
\text { applied load }\end{array}$} & \multicolumn{2}{|c}{ Reduced weight $[\mathrm{g}]$} \\
\cline { 2 - 3 } conc-conv./120 Nm & 0.115 & 0.198 \\
\hline conc.-conv./190 Nm & 0.198 & 0.351 \\
\hline spur $/ 120 \mathrm{Nm}$ & 0.178 & 0.282 \\
\hline spur/190 Nm & 0.280 & 0.398
\end{tabular}

measurements were performed at specified points and wear values are determined (see Fig. 6).

In addition, the temperature changes occurring at the contact points of the gears have also been detected on the abrasion bench (Fig. 7).

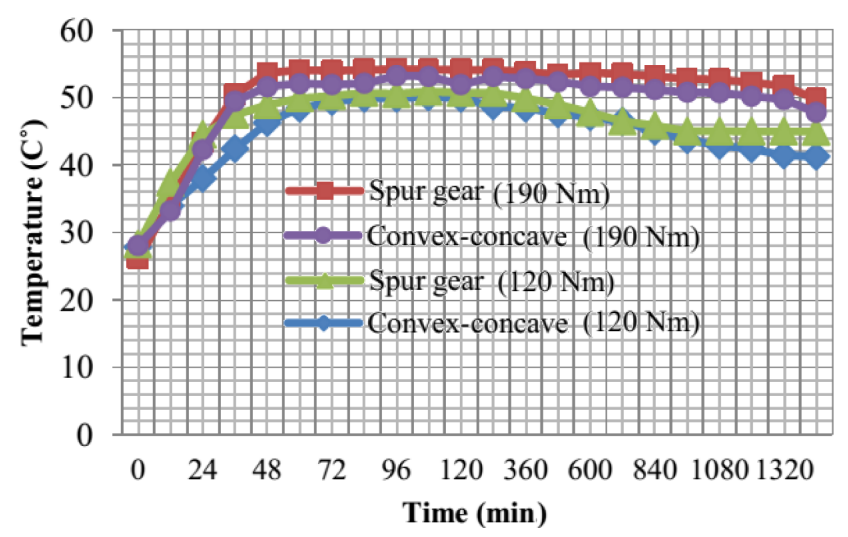

Fig. 7. Temperature changes occurring at the contact points.

\section{Conclusion}

In this study, the wear behaviors of the curvilinear involute-profile gears and spur gears have been determined. As a result of the experiments, it has been seen that the weight losses of the spur gears were within the range of $0.178 \mathrm{~g}(\mathrm{~min})$ to $0.398 \mathrm{~g}(\max )$, which were subjected to two different loading applications with rotation rates as $1.8 \times 10^{5} \mathrm{rev} / \mathrm{min}$ and $3.6 \times 10^{5} \mathrm{rev} / \mathrm{min}$. These values have been observed within the range of $0.115 \mathrm{~g}(\min )$ to $0.355 \mathrm{~g}(\max )$ for the curvilinear involute-profile gears under same conditions. According to these results, it is obvious that the curvilinear involuteprofile gears are more resistant to abrasion than the spur gears. In addition, considering the temperature distributions during the study, the temperature occurred in the curvilinear involute-profile gears during operation is lower than the temperature occurred in the spur gears. In addition, considering the measurements of solid models produced by 3D scanning method, it can be easily observed that the wear in the spur gears is higher than the wear of the concave-convex toothed gears. According to the studies in the literature, comparing these two types of gears; it has been determined that the concave-convex toothed gears have more capacity for load bearing than 
the spur gears and they work quieter. In this study, it has been determined that these gears are better than spur gears in terms of wear behaviors and the temperature values occurred at the contact points during operation were found to be lower in the concave-convex toothed gears. As a result of this study, advancement has been achieved in terms of ensuring the usability of these toothed gears in the industry by proving their advantages compared to the spur gear. Since these toothed gears can be produced by CNC machines easily and their advantages have been proven in many areas, these gears can find more areas of usage compared to the spur gears.

\section{Acknowledgments}

This study was supported by BÜBAP unit of Bingol University.

\section{References}

[1] S. Orhan, N. Akturk, J. Fac. Eng. Arch 18, 97 (2003).

[2] A. Flodin, S. Andersson, Wear 207, 16 (1997).

[3] I. Huseyin, Ph.D. Thesis, Selcuk Universty, Konya, Turkey, 1995.
[4] P. Bajpai, A. Kahraman, N.E. Anderson, J. Tribol.126, 597 (2004).

[5] W. Shifeng, H.S. Cheng, Trans. ASME J. Tribol. 115, 493 (1993).

[6] F. Anders, S. Andersson, Wear 249, 285 (2001).

[7] A. Singh, D.R. Houser, S. Vijayakar, in: $A S M E$ Power Transmission and Gearing Conference, DE-88, 1996, p. 673.

[8] D.P. Townsend, Dudley's Gear Handbook, Mc GrawHill, New York 1992.

[9] M. Uzun, C. Ozel, 6th International Advanced Technologies Symposium. Turkey, 2011, p. 16.

[10] M. Uzun, A. İnan, J. Braz. Soc. Mech. Sci. Eng. 37, 255 (2015).

[11] M. Uzun, A. İnan, J. Test. Eval. 44, 20140095 (2016).

[12] H.İmrek, H. Düzcükoğlu, Wear 262, 390 (2007).

[13] K. Aslantas, S. Tasgetiren, Wear 257, 1167 (2004).

[14] ASTM Standard, D5182-97, Annual Book of ASTM Standards, 2002.

[15] Deutssche Norm, FZG-Zahnrad-Verspannungs- Prufmaschine, DIN 51354, 1990.

[16] ISO 6336, Calculation of load capacity of spur and helical gears, 1991. 